large during an extended period, and then compare the results with those of hysterectomy.

64 Riehmond Avenue.

\section{OPERATION FOR RECURRENCE OF CANCER AFTER HYSTERECTOMY**}

\section{E. W. CLSHING, M.D.}

Professor of Abdominal Surgery and Gynecology, Tufts üniversity. BosTon, MASS.

\section{FREQUENCY OF RECURRENCE.}

Sad and discouraging is the fact that a very large number of cases of cancer of the uterus recur after a variable time subsequent to the removal of the organ by hysterectomy. Nevertheless, this is not a reason for abandoning the operation, which certainly saves a great many cases, prolongs the life of more and mitigates the sufferings and grants a comparative euthanasia to the rest.

Early diagnosis, immediate surgical interference and more thorough methods of opcrating are constantly giving better results. Just as in mammary cancer the modern methods of removing the contents of the axilla and all the tissues between the axillary glands and the mamma, together with the subjacent muscles, as well as the whole breast and overlying skin, have vastly improved the final results, so the thorough operation for hysterectomy in cases of cancer, with dissection of the space at the bifurcation of the iliac arteries, removal of the glands and lymphatics, liberation of the ureters, complete ablation of the bases of the broad ligaments and avoidance of infection of the cut surfaces by finally removing the uterus through the vagina, after it has been liberated and all vessels ligated from above through the abdominal incision, will give vastly better final results in cancer of the uterus.

PROBABLE RECURRENCE NOT A CONTRA-INDICATION.

I would insist, however, that even in cases in which the diagnosis has not been made so early as could be desired, or in which the condition of the patient, or the skill of the operator does not admit of the improved and thorough operation as described above, the ordinary methods of hysterectomy will give results which fully justify an operation in all cases in which the whole of the disease can apparently be remored. If in too many cases there is a recurrence, when it is not expected, yet in others in which recurrence seems inevitable, it does not occur, and $I$ have patients operated on ten or twelve years ago for undoubted cancer of the cervix uteri, who are alive and well to-day, although the operation was difficult owing to considerable progress of the malady.

There is abundance of evidence to show that there are resources of nature which combat the cancerous infection, and sometimes they overcome it, although too often they fail, even when the principal seat of the disease has been removed. Presumably, however, the cases in which there is no recurrence are those in which, although the growth is exuberant or the uterus deeply ulcerated, there is no infection of the lymphatics and the vaginal incision has not been infected at the time of operation.

In the other cases, after a variable time from a few weeks to several years, the dread disease is found to have persisted and is manifested either by a failing of the general health, owing to a so-called metastasis to some of the vital organs; in which case, of course, nothing can be done to oppose it, or there is found a hardening and

* Read at the Fifty-third Annual Meeting of the American Medical Association, in the Section on Obstetrics and Diseases of Women, and approved for publication by the Executive Commin.
Drs. A, H. Corder, W. E, B, Davis and Henry P. Newman. thickening in the roof of the vagina, or a mass in one or both broad ligaments.

\section{COMMON TREATMENT OF RECURRENCE.}

Now, these cases of local recurrence, or persistence, are considered so hopeless that little or nothing is done to attempt to arrest the disease. Patients are not kept under proper surveillance after hysterectomy, examinations are not made with the object of detecting the first manifestations of the disease and if perchance the patient is warned by discharge or hemorrhage and comes to consult the surgeon, it is only rarely that some help. is offered in the way of exsecting or cauterizing some small point in the line of the previous incision, while if there is a mass, even a small one, in the broad ligament, no hope is usually held out that anything further can be done.

Meanwhile the patient is often in better condition., physically, than at the time of the original operation. Months or years of freedom from the wasting discharges and from the absorption of putrid matters have allowed her to gather strength, the desire of life has grown strong again and the disappointment at finding that all previous surgical interference has been in vain is doubly cruel and intolerable.

I have seen too many such cases, both after operations of my own and of others, and too often I have sadly pronounced the words of doom to disheartened relatives or evaded a direct answer to the patient, wishing to leave her a little more time for hope and enjoyment of life.

Some years ago I saw a lady in whom five years after hysterectomy for cancer there was a slight hemorrhage, and examination showed a mass as large as an almond in the right broad ligament connected with a little granulating point in the right angle of the scar in the vault of the vagina. I Last spring and summer I watched the life ebb slowly away from the wife of a physician from recurrence in the vaginal incision noarly a year after hysterectomy had been performed bv another surgeon for cancer. I made an attempt to remove the diseased tissue from the vault of the vagina, as a palliative measure, but knew that the benefit would only be temporary, because under ether I could trace the infection running up into one broad ligament.

REMOVAL OF A RECURRING CANCER.

I then determined that if a suitable case occurred to me I would perform a radical operation through the abdominal wall, modeling it on the modern operation for cancer of the uterus. (Rumpf-Riess-Clark-WernerPryor.) Therefore, last January I operated accordingly on the following case:

History.-Mrs. M., aged 58, in good health, notices slight hemorrhage and discharge in May, 1901. The nterus was curetted and the specimen pronnunced malignant by Dr. Whitney, and more complete examination of the uterus after removal showed that the growth was an adenocarcinoma of the cervix.

Initial Operation.-In July, 1901, the uterus was removed by a very competent surgeon, who first curetted and made an incision around the cervix in the vagina and then opened the abdomen and removed the uterus. Convalescence normal. Great subsequent improvement in health and strength.

Recurrence.-Six months afterward, in January, 1902, the patient was surprised and distressed at finding that she had a slight bloody discharge. I was consulted and found at each end of the scar in the vauit of the vagina a small patch of granulations, each patch being about half as large as the little. finger-nail and evidently malignant. Bimanual examination, especially when made per rectum, disclosed a small elongated: mass, most marked on the right side, extending outward and 
upward and obviously lying in the stumps of the broad ligaments.

It was plain that the whole of the disease could not be removed per vaginam without the greatest danger to the ureters and then with no certainty as to the completeness of the eradication of the infected tissues. The whole situation was explained to the patient and her husband and, without hesitation, they demanded the most thorough operation that could be performed, assuming all risks of a fatal result of the operation and holding such a death an event preierable to that of a miserable wasting away with a hopeless disease.

Second operation.-On opening the abdomen it was at first impossible to keep all the intestines out of the pelvis, although the patient was in the full Trendelenburg position, therefore some part of them was kept in hot wet cloths on the surface of the abdomen, until a little later in the operation, when it was returned into the abdominal cavity. There were very few adhesions; the round ligaments ran to the stumps of the infundibulo-pelvic liganents, making a band on each side of the pelvis, with a little mass on each side where the silk ligatures on the ovarian arteries were felt beneath the surface. The stumps of the broad ligaments could be felt, somewhat thickened, and with the ligatures likewise in place.

An incision was made across the bladder, about one centimeter above the scar of the former incision and with great care and some difficulty the bladder was dissected free from the tissues of the vagina. As there was much cicatricial substance in this locality this dissection was rather obscure, and was not carried very far at this time from fear of wounding the ureters.

Next the peritoneum was divided on the right side from the end of the incision over the bladder, passing above the stump of the broad ligament and below the stump of the ovarian artery as far as the brim of the pelvis. The bifurcation of the iliac arteries, and the course of the ureter in this vicinity was now exposed. At the junction of the arteries were some glands, one of which was three millimeters in diameter and another sornewhat smaller. The glands and all adjacent tissues were very carefully removed, and the ureter was traced and separated as far down as where it passed into the broad ligament. Here trouble began as the ligalure on the uterine artery was very close to the ureter, and in trying to dissect out the latter it was mistaken for the former and cut. The distal end was immediately found, however, and the dissection of the ureter continued until it was free from the broad ligament and near its entrance to the bladder.

The uterine artery was next followed to near its origin and there tied, when the whole of the right side of the pelvis was cleared out much as the axilla is emptied in the corresponding dissection for mammary cancer.

The severed ureter was now repaired by Van Hook's method. carrying the proximal end into a slit in the side of the distal portion, near the extremity of the latter. I regretted that bougies had not been introduced into the ureters before the operation, which would have prevented the accident to the ureter. I had omitted this precaution from a desire to save the additional time under ether, as the patient was neither young nor very strong. I believe, however, that with experience and care and by beginning at the junction of the iliac arteries the ureters can be safely dissected out, without the use of bougies, although there are obvious and great advantages in using them.

The next step of the operation was to carry an incision through the peritonemim on the left side, similar to the one described on the right side, as far as the junction of the iliac arteries. Similarly the glands were removed, although they were much smaller, the ureter was carefully dissected out to the base of the bladder and lifted out of the way, the uterine artery traced and tied at the side of the pelvis and the broad ligament and other pelvic contents separated.

An incision of the peritoneum was now run across between the old scar and the rectum, when the top of the vagina was seized and drawn up as far as possible, and I apidly freed from the rectum and the bladder and cut across below the seat of recurrence.

By this time the patient's strength seemed to be failing, and without waiting to unite the incisions in the peritoneum, a thickly-folded piece of gauze was drawn from above downward through the vagina, the upper end extending just into the pelvis.

The ureters were laid as far as possible in their normal positions and the peritoneum drawn into place and a Miculicz pack of moderate dimensions introduced through the abdominal incision, which was then closed around the gauze. Duration of operation one and one-half hours.

Results.-Recovery uneventful; slight leakage of urine through the abdominal incision after removal of the pack. This fistula has not yet entirely closed, but sometimes it closes for a week or more and then will reopen and allow a little urine to escape. General health excellent six months after the operation. No recurrence locally.

\section{COMMENTS ON THE CASE.}

From my experience in this case I see no advantage in Van Hook's method of uniting the ureter over the end-to-end method which I used in my previous case of severed ureter, reported to the Philadelphia Obstetrical Society in 1893. If I ever have another case I shall use the modification which I have found of service in uniting the ureter with the bladder through the vagina, viz., to do it over a catheter. I would therefore pass a catheter down through the distal portion of the severed ureter into the bladder and out through the urethra, and slip the upper end of the catheter into the proximal end of the ureter and unite the latter carefully end to end over the catheter, which can safely remain in place for a week or more.

To avoid as far as possible all chance of infection recurrence in the case of this patient, three weeks after the operation, the vault of the vagina all around the cicatrix was dissected away and the edges of the wound united with catgut. thus removing the tissues as widely as I would have done at the first operation had the strength of the patient permitted.

I have reported the steps of this operation somewhat at length because $I$ have not been able to find a report of any radical operation for removal of cancer, recurrent or persistent, after hysterectomy, and because the absence of the uterus and the presence of ligatures and cicatricial tissue confuse the natural relation of the parts and render the dissection more difficult. Nevertheless, if a close supervision is exercised over patients after hysterectomy a large number of cases will be found in which such an operation is indicated and warranted.

of course, when the radical operation has been done in the first place, there will be no probability that anything can be accomplished by a subsequent operation, but I think that recurrences will be rarer in proportion, as the first operation is more thoroughly and carefully performed. It will be a long time yet, however, before the radical primary operation will be the rule, for many surgeons will be disinclined to perform it, and in many patients the conditions will not warrant it, owing to weakness from hemorrhage, discharges, etc.

When, under these circumstances, the disease is found to have manifested itself at a subsequent examination, I feel sure that such an operation as is here reported will be found feasible and indicated. I hope that my experience in this case may encourage others to attempt to save some of the unfortunate and hopeless women who in the past have been considered as inevitably doomed. 
EXAMINATION OF TISSUES REMOVED.

Following is a report by Prof. T. L. Leary on the tissues removed from Mrs. M. at Cushing Hospital:

Pathology.-Specimens consisted of vault of vagina with stumps of broad ligaments and pelvic connective tissue; portions of right round ligament which had been included in the ligatures at previous operation; pelvic fat tissue from region of iliac arteries and iliac lymph nodes.

The great mass of tissue is attached to the vaginal vault. The vaginal mucosa presents a smooth surface, concave- $5 \times 3$ $\mathrm{cm}$.- showing on either side of the middle line bilaterallyabout $3 \mathrm{~cm}$. apart-two dimple-like depressions.

From the right one projects a fungous growth of rather flattened papillary masses which stand up $.5 \mathrm{~cm}$. above from smooth vaginal surface. The other shows only a conical depression ending in a pin-head opening which admits a small probe for $1.5 \mathrm{~cm}$.

Microscopic Examination.-Section through fungous growth on right shows a mass of reddish-gray soft tissue, continuous with the papillary growth and extending for some distance into the surrounding tissues from which it is easily distinguished on account of its darker color and softer consistency. This growth is apparently wholly included within the tissue removed.

Incision along a probe introduced into opening on left side of vault lays open a canal lined by flattened masses of soft tissue corresponding to that described on right side. 'This tissue extends well beyond the limits of canal admitting probe and into the scar tissue and pelvic connective tissue above vault. As on the other side, all of growth is apparently included in tissues removed.

The upper portion of the mass (i. e., above vaginal vault), as well as the tissues included with fragments of right round ligament, eontain many large braided silk sutures imbedded in dense scar tissue.

Most of the iliac fat as well as the lymph-nodes imbedded in it are free from gross evidence of any new growth. A single iliac node removed just below the bifurcation of the common iliac artery is enlarged to the size of a split pea, is firm and of a pale gray color.

Microscopic examination of sections of papillary growth on right side show it to be made up of broad masses of epithelial cells, which occur for the most part in branching trabeculæ running at right angies with the surface. Many of these trabeculæ enclose spaces which suggest gland cavities. Much of the tissue on the exposed surface (vaginal) of growth has undergone necrosis-the cells stain poorly and there is an acute inflammatory reaction. The junction of new growth with normal tissues is marked by collection of lymphoid and plasma cells. Gross sections about $3 \mathrm{~mm}$. apart were made from all of the suspicious tissues about vaginal rault. Microseopic sections from these show in every case where new growth was included, a picture corresponding to that described alove. The growth is apparently sharply localized, since no metastases are discoverable in the tissues outside of the main tumr masses. The tissues exeiserl show everywhere a corssiderable margin of normal tissue outside of new growth. At one point on left side, where in gross it appeared to be questionable whether a sufficiently wide margin of normal tissue had been obtained, microscopic examination demonstrates a larger amount of normal tissue outside of tumor tissue than had been expected.

Mieroscopic examination of sections from pelvic fat and the tissues of broad ligaments shows no metastases even lymphatic. Mieroscopic examination of twelve sections representing about 150 sections through iliac lymph node shows dilatation of lymph sinuses, which are filled with granular material (coagulaled lymph?), and slight hyperplasia of follicles. There is absolutely no evidence of metastases in the node.

$$
\text { NARRATION OF SECOND CASE. }
$$

CASE 2.-Mrs. Y., aged 50, had the utertis and appendages removed by me five years ago, for carcinoma, by vaginal hysterectomy. Since that time she has enjoyed good health until some six months ago, when she began to complain of pain in the ieft side, and of some dificulty in walking. Within a month she had a slight hemorrhage and consulted a physician who told her that the disease was coming back, and advised her to see me again.

On examination there is a movable mass in the left angle of the cicatrix of the former incision. with a small sprouting growth of malignant tissue. The mass is about two em. in diameter, slightiy attached to the mucous membrane and apparently pretty free in the connective tissue above.

There are very large veins in the left hypogastric region of the skin of the abriomen, the importance of which was recognized, but on the whole it seemed best to open the abdomen. When this was done the right side was found to be wholly normal. The mass on the left felt on preliminary examination could have been removed as in the previous case, but higher up, at the junction of the iliac arteries, there was a larger mass, immovable and intimately connected with the ureter and the internal iliac vein, which last was occluded, while the mass encroached on the external iliac vein so that to remove the growth it would hare been necessary to splice the ureter and to tie the common iliac vein, with no certainty that it would have been possible to respect the artery.

While surgically it might have been possible to remove the mass, yet in view of its malignant nature it seemed better to desist from further operative attempts, as I accordingly reluctantly did. The patient is now slowly failing, some three months after the exploration.

I report the case in view of the interesting symptom of collateral circulation through the superficial veins, and from the light it throws on the progress of the disease.

\section{DISCUSSION}

ON THE PAPERS OF DRS. FREJERICK AND CUSHING.

Dr. G. B. Massey, Philadelphia-Mr. Chairman: I do not think that the report of a few cases of hysterectomy for cancer where the microscope failed to reveal malignant disease should discourage an attempt to cure it by its early removal. Better remove some normal uteri than risk delay. But $\mathrm{I}$ again want to call attention to what I regard as a better operation for cancer of the cervix, one which is applicable to the primary condition, and also as a palliative remedy in cases of recurrence. I have not used this method in more than six cases, only one of which was primary and operable. That case is still living after five years. The diagnosis was verified by the microscope and concurred in by the late Dr. Parvin of Philadelpinia. The other cases were cases of recurrence, and none were cured, although palliation was marked. I do not wse the knife, but the method is surgical in the strictest sense of the word, and there is even a mortality attached to it, I regret to say. The methorl is absolutely aseptic and antiseptic. It is a modification of the cancer method which I brought before the profession first about seven years ago. The electric salts of mereury manufactured by electrolysis on a massive scale inside the patient's body are used to destroy the tissues and sterilize the surrounding region. The modification consists in the use of zine points coated with mercury, because it is practically impossible to keep liquid mercury in contact with gold instruments in the place where you want it in these cases. The material formed is a nascent oxy. chlorid of mercury and zinc, and all who have used the chlorid of zinc as a mere contact remedy know of its caustic qualities. In this process the nascent salts are diffused through the tissues by electric osmosis, the current sending it along the lines of least electric resistance, which are the lines of greatest cellular proliferation. Une application will destroy the odor for fourteen days absolutely. It is bloodless, and thoroughly sterilizes the tissues. Whether we can cure inoperable enses by frequent repetition remains to be seen. One advantage of this method over the curette in these hopeless cases is that not a drop of blood is lost. The blood ressels are closed up and the patient gains color inside of a week, because she is no longer absorbing septic material, and is regaining her accustomed vigor. In my five recurrent, inoperable 
cases life was prolonged, with inmense increase of comfort, from three to six months.

Dr. E. E. Montgomery, Philatelphia-Every contribution on this subject made as earefully as that with which Dr. Frederick has favored us is of value in throwing light on a disease which so far is the most difficult the surgeon is called on to treat. While the statistics he has given us go to show that amputation of the cervix is a desirable procedure, yet my own experience convinces me that it is desirable to get rid not only of the cervix but of the entire e rgan. It is true that we lind, in the great majority of cases, that the disease returns in the vagina, sometimes extends and involves the tissues some distance from the line of the cicatrix, just as the surgeon finds in the removal of the breast, although the giands in the axilla are extippated, the disease subsequently returns in the skin, either in the cicatrix or near it. This is due to the fact that in the development of the disease in the cervix we have some of the lymphaties plugged, but the tissue being very rich in lymphatics, the current is carried in another direction, and we have a subsequent recurrence of the disease in a new field. No matter whether we amputate the cervix or remove the entire organ, the disease invariably recurs in this way.

With regard to the squamous disease, my own experience has been that, with careful attention to getting well beyond the disease to prevent a re-infection by portions of material that may be left behina or fragments that may be broken off and subsequently come in contast with the wound, that it is the most amenable form of disease with which we have to deal. The glandular variety begins in the cervical canal, rapidly penetrates the wall of the cervix, and the perimetric tissue soon becomes inrolved. The tendency to re-development is very marked in these cases in spite of any operation that may be done.

In either class of cases I believe the cautery is more applicable simply because heat has a tendency to destroy or arrest the development of the disease in the tissues which are well supplied with blood. The diseased tissue is affected more by the heat than the connective tissue, and we may look forward to a more thorongh removal and longer lapse of time before its return than with the ordinary method-the use of the knife and scissors. The fact has been mentioned that in the high operation we have the formation of granulation tissue and great care must be exercised in bringing together the uterus and the vaginal mucous membrane. The formation of cicatricial tissue, the occurrence of dysmenorrnea or the retention of secretion in the uterine canal, with increased discomfort to the individual, would seem to me sufficient reason why we should remove the entire uterus.

With reference to the danger connected witl any operation, in the hands of operater's as careful as 1)r. Frederick, $\Upsilon$ doubt whether there is a greater mortality in hysterectomy than in amputation of the cervix.

I wish to express my high appreciation of Dr. Frederick's paper, and $I$ am convinced that if more of us would exercise the same care we would greatiy advance the study of this subject.

Dr. Chiarles P. Noble, Philadelphia-I can not but appreciate Dr. Frederick's paper, although $I$ am not such a pessimist as he. I think cancer is the most terrible disease we have to deal with. During the last year I tabulated my own results in dealing with cancer, from the standpoint of how many cases had recurrence after operation, including both cancer of the uterus and the cervix, and 20 per cent. remained free from recurrence for five years. That included a large number of cases of cancer of the body in which the prognosis was much more favorable than in cancer of the cervix. In operable can. cer of the cervix we can, with the present methods. have at least 10 per cent. of cures, taking five years as a basis, and I think we can improve on that very much. Of course, this subject is being studied very widely, and our German trienas have given us very encouraging reports in the last year.

My own feeling about the question of how to deal with cancer of the cervix is that in early cases we should do a very radical operation and then we would get a very high per- centage of cures. It is in cases that approach the borderline where my personal experience has been that we get a high mortality in deing hysterectomy, and in future I shall do a more radical operation on the early and the temporizing operations in cases approaching the border-line, either amputating the cervix or burning out the mass with the cautery or electro-thermic clamp, and then, when the patient recovers and her vital resistance is betler, I will do a radical hysterectomy. I belheve hysterectomy is the operation of choice, unless the bacteriologists can give us some serum to use in these cases. If the patient is in good condition, we should be radical. In broken-down cases it is my judgment that the good name of surgery will be conserved by doing a temporizing operition.

Dr. William H. Humiston, Cleveland, Ohio-This is a subject in which $I$ am very much interested, and I will add my experience in the treatment of carcinoma of the uterus by operative measures. I have been engaged in operative work for the past fourteen years and I have not one case of carcinoma of the cervix alive to-day on which I performed a radical operation where the symptoms-hemorrhage, pain, and an odorous discharge-were present.

The eases we see, as a rule, have been progressing until these symptoms appear, and I believe these cases always recur after operation. Cases that permit of a conserving operation live anywhere from three months to a year.

One of my most interesting cases was a young married woman of twenty-eight, who had beell treated for some time, for a so-ealled ulceraticn of the os, by caustic applications. When she came under my care there was a very suspiciouslooking cervix, uterus fixed, masses in both vaginal vaults, and I beiieved that she had a malignant disease of the cervix, as well as pus in the tubes. I took out a section of the cervix for mieroscopic examination and earcinoma was diagnosed.

Being a young woman and having this pus formation in the pelvis. a rare and urique condition in my experience, $I$ advised total hysterectomy, which was consented to. I removed the cervix tirst and euretted the borly, swabbing it thoroughly with the compound tincture of iodin and carbolic acid. I then remored the uterus. She recovered promptly, but within six months nodules were ielt in the line of incision and in the inguinal region above.

In this young case, then, where the disease was apparently limited to the cervix, and where the hemorrhage and odorous discharge were slight, she did not live a year. We must have these cases very early if operation is to be successful.

Every suspicious cervix must be examined microscopically, and operated on before we have the trinity of symptoms, pain, hemorrlage and odowus discharge. On the other hand, my success with malignant disease of the body of the uterus has been phenomenal.

In all these cases that have bcen discovered by microscopic. ally examining scrapings of the uterus, a procedure 1 never fail to carry out-and where an hysterectomy is done promptiy - every one of them is alive to-day.

Dr. L. H. Dinning, Indianapolis-I am surprised to hear the high rate of mortality given by one of the speakers, because it has a tendency to discourage all other operators. It has a tendency to bring disrepute on an operation which, It it is not life-saving in many cases, is palliative in very many. My own experience shows that in cancer of the cervix, where the uterus is freely movable, at least 15 per cent. of the patients survive five years. I must say, however, that the five-year limit does not always indicate that there will be no recurrence. I have hard two patients who had been placed in the list of cures, who died from recurrence, one after six years. and the other after seven years. So I think we ought to be careful not to let it appear that every case operated on by hysterectomy dies of cancer, as from 10 to 15 per cent. are usually cured.

Again, I do not believe that we ought to allow it to appear that the operation of high amputation of the cervix is attended by little or no mortality. You will remember Schroeder's statistics some twelve or fifteen years ago, which showed a mortality of 9.6 per cent. from high amputation of the 
cervix. We must also remember the character of the cases operated on, a point which was brought out admirably by Dr. Montgomery. Cases involving the vaginal portion of the cervix only are those that should receive a high amputation. Those cases in which the cancer deveiops between the external and internal ora are unfavorable for this operation. Those who do hysterectomies, will remember their experience in dealing with those cases. You attach the vulsellum forceps and attemupt to pull down the uterus. In many cases you pull off the cervix, thus embarrassing the whole operation. You must also remember how very high up the disease extends on either side of the cervix. Those are exceedingly unfavorable cases for high amputation. They recur very rapidly, and the mortality is high. The curette can not be used, nor can we use the thermo-cautery with any degree of safety. Even hysterectomy should not be done in these cases unless the uterus be freely movable.

In about 10 per cent. of the cases of cancer of the uterus we will have involvement of the uterine appendages, and this may be cf considerable importance, for the reason that if our patient survives six months or a year we wish to give her as much comfort as jossible. If we leave behind a pus tube or an inflamed ovary, we can not give that patient the greatest degree of comfort. About fifteen years ago I advocated high amputation, but 1 gradually worked out of that. One of the things that led me to adopt a rifferent plan of treatment was that where we did a total extirpation, with removal of tubes and ovaries, not only as many cases recovered, but the future condition of the patient was very much better. They suffer less, gain strength more rapidly, and have no painful menstru ation. I think we should be very loth, indeed, to ignore the lesson we learned ten or twelve years ago, that we have fewer recurrenecs after a total extirpation, and greater comfort to the patient.

Dr. Gustav Kolischer, Chicago- In discussing such an important subject as eancer of the uterus, it is very important not to deal in generalities but to use exact figures and terms to bring forth exact facts. Cancer of the cervix, for instance, is to-day an absolutely insufficient and rather unscientific term. We must distinguish between eancer of that part of the cervix which protrudes into the vagina and the part intermediate between the portio vaginalis and the uterine body. The importance of this distinction is especially shown by Winter. Cancer in the upper part of the cervix is more dangerous because the envolvement of the parametric tissue sets in quite early. Secondly, it is necessary to understand that under the term recurrence two entirely different conditions are thrown together. Recurrence is the development of cancer from cancer cells which have been left outside the reach of the operation. The appearance of eancer in the vaginal superficial tissue, for instance, is not a recurrence but the appearance of cancer inoeulation. This inoculation is due to imperfect technie, that is insufficient covering up of the exulcerated part of the carcinoma. Poor technic is also to be held responsible for some recurrences, because the operation did not extend far enough into the parametric tissue. Many operators making a hysterectomy do not try to remove as much parametric tissue as possible, but try to get through as quick as possible. In such rases, you can judge the technic of the operator simply by looking at the specimen. The removed uterus looks like a peeled off piece of a eausnge instead of carrying tise parametria on both sides, like wings. The same is true of the clamp operation. We lose too much space, space which ought to be used for applying ligatures as cluse as possible to the pelvic frame. The supposition that the heat of an electric clamp destroys eancerous cells in the adjacent tissue shows an optimism which is not justified by the results of igni-extirpation of the cancerous uterus. So far as envolvement of the bladder is concerned, Dr. Frederick sair that the bladder wall becomes envolved early. This statement is erroneous. As a rule, it is the last tissue which is invaded. In about 150 cases of inoperablis carcinoma, which I examined, the bladder was envolved in only 15 cases. As to mortality immediately following hys terectomy for cancer, it is undoubtedly high. The best operators report the total mortality as 10 per cent. The necessity of removing the uterus in all cases of cancer, no matter where it is located, becomes apparent from the following consideration: There are cases on record where cancer of the cervix or portio was combined with cancer of the uterine body.

Second, we know of cases where, after liysterectomy was performed, cancer developed in the appendages which were left. Recurrences do not appear in the vaginal scar but in the parametric tissue or in the lymphatic glands, so we have no reason whatever to return to the excision of the cervix, but we have to make hysterectomy, including the appendages, after methods which allow of extensive removal of the parametric tissue; that is, performing vaginal hysterectomy, using Schuchardt's incision, or the first by Ries' proposed abdominal operation. So far as statistics of recurrence after vaginal hysterectomy for a cancer of the cervix and portio are concerned, Winter, whose statistice are recognized as the best ones, reports between 5 and 15 per cent. of definite cures, according to the kind of cases. As to Dr. Cushing's case, his intention to try to operate for a recurrence if we can is undoubtedly a good one. So far as his diagnosis is concerned, I am rather inclined to think that in his case not a cancerous recurrence was present but an inflammatory infiltration. For this view speaks the short time which the formation of the tunior took and the ease with which the operation could be performed. If we make laparotomy for cancer of the uterus and find that the neoplastic infiltration extends into the ligament it is next to impossible to finish the operation.

Dr. W. H. WarheN, Louisville-I want to disapprove of high cervix amputation for eancer, or any operation that is not radical; remove not only the entire organ, but as much tissue beyond as can be removed without injuring the ureters and surrounding structures. Where permanent cures are so frequently reported in high amputations, I can not believe that the reports have been accurately taken. I am sure there was a mistake in diagnosis in most of these cases. The term eancer of the uterus is a very vague one. We must consider it as involving the cervix, and extending up into the uterus or out in the broad ligaments, or a cancer that is protruding into the vagina, without deep involvement of any other structure. In the first instance, if the disease has gone beyond the parenchymatous structures into the broad ligaments, it does not matter what operation we perform, 99 per cent. will recur. If it has not gone beyond the parenehymatous structures, or if it is confined mainly to mucols structures, it may not recur if operated on promptly. If protruding into the vagina many cases will recover if the disease has not progressed too far, and if the case is properly operated on.

I have a case now that was operated on six and a half years ago, and she is still in perfect health. The cancer was as large as my fiat, and the symptoms were typical. It was located in the neck of the uterus. If you can get these cases in time, before disease has spread, it may not recur, but if the eancer has involved the glandular structures of the pelvis, we do not knuw where it will end. I do not believe in the removal of these glands, because they are so numerous that we can not remove them all. A gland no larger than the end of a pencil is as dangerous as a gland the si\%e of your fist.

Dr. Edwis Ricketrs, Cincinnati-I do not think it is fair to criticise a man who gives us an honest report of 482 operations for cancer of the uterus, with two of them living. With all due respect to Dr. Kolischer, who made the assertion that the technic was faulty, let us be true to ourselves, and true to our patients. Although the results in all operations for cancer of the uterus have been most unsatisfactory, we ought not to let up in any way. You may work along the line of electrolysis, total extirpation, or high amputation, but do not let up in your best efforts for a possible cure of the disease. You may theorize as much as you please, but when you come down to this simple question, I must say that I, for one, have been greatly disappointed. I question very seriously any man who says he has 10 per cent. of cures in cancer. The operation for cancer of the uterus should be classified, and I do not think it is fair that we have to produce statistics including cases we accept as inoperable, and consider them on a line with those cases that improve. Personal experience does not go very 
far in the consideration of this subject. We can arrive at definite conclusions only as the result of consensus of opinion of the medical profession.

DR. H. O. MARCY, Boston-For ten years this Section has been discussing ihis question, and I do not doubt that for ten years to corne we will find the same difference of opinion as to minor details. Of course, it is an important subject, and yet the experience of most of us has taught us something. Ten years ago the majority of operative surgeons were using the method advocated by Dr. Frederick, but most of us have eliminated this method of high amputation, and we do a more thorough operation. My own method is to remove the tissues as far as possibie from the seat of the disease, open the abdomen, and remove the appendages and surrounding tissues as far as $I$ can. I am sure I ain getting better results, and I have patients living and well after more than five years. If this be the better method, why is it not the method we should use instead of returning to earlier ways? After curetting and cutting away as far is possible, I used to pack the vaginal vault with wet cotton, and then introduce the thermo-cautery, expecting that by steaming I could penetrate the tissues more deeply. The more thorough the method, the safer the result. I am certain that the general consensus of opinion is away from the conclusions of the speaker, and more toward conservative, wise, aseptic operation of the most efficient type for removal of malignant disease of the pelvis.

Dr. A. J. Downes, Piniladelphia--In my paper yesterday 1 made some remarks about cancer of the uterus. Every surgeon who has written about hystereetomy tor eancer involving the cervix admits a recurrence of alnost 99 per cent., to be correct, by the common methods of operating. If Dr. Burns' eases were examined microscopically and the results as iepored are true, it appears that there is something in the use of the cautery for cancer of the cervix. It is important to know this, for it is just as safe, if one can do a practically bloodless operation, to remove the uterus after having first amputated the cervix, as it is to do a cervix amputation alone with the cautery knife. I have adopted this method in three rases, two of them advanced with the cervix fixed. In each case the cervix was first amputated by the cautery knire and the remainder of the uterus then removed by the electrothermic angiotribe in the blades of which were included the broad ligaments. The operation is completed by making section close to the inner surface of the blades. This leaves a broad ribbon of seared hemostased tissue on each side of the pelvis, which is non-exuding, non-adhering and non-absorbing. In the last case, in which I also opened the abdomen, after thoroughly removing the uterus, one of the blades of the small forceps, which heats water in five seconds, was applied to each side, in the para-cervical region, with a view of transmitting heat through the infiltrated area, care being taken not to come in contact with the ureter. These cases do better than where the ligature is used. No blood is lost, except in making the incision into the peritoneal cavity at the cervix, or in making a too rapid sweep of the cautery knife. The point involved is that we not only go deeper into the tissue of the broad ligament, but we leave it sterile and sealed. The mortality rate shoild not exceed even that of amputation of the cervix

Dr. J. H. Carsters, Detroit-The more I see of cancer, the fewer vaginal hysterectomies I do. I have found that these bad cases on the border-line are those that give you a large mortality. The results are very poor, so that $I$ prefer to have a less immediate mortality, and prolong the patient's life by curetting, high cervix operaiion, cauterization, etc., reserving the radical operation for those cases which, in my own mind, have a good ehance of making a permanent cure.

Dr. FREDERICK (closing the discussion on his part)-This discussion has brought out the fact that a fair proportion of men doing operations for cancer of the servix do a radical operation for nearly every case. even when the broad ligaments and perimetric area are involved. I am talking about purely operable cases, where the disease is confined ti the cervical tissnes, and does not go beyond the confines of the cervix. That alone is an operable case. You have recurrence every tisie, if there is any involvement of even the outer limits of the cervix. You can not prevent it. There is only one class of eases in which you are justified in doing a total extirpation, and that is where the disease is confined to the cervix, so far as you can prove it. Facts are facts, and $I$ have here the report of over twelve hundred operations, from men like Price and Kelly and MacMonagle. Dr. Kelly has had four recoveries over five years old out of many over a hundred. Your all adruit that these men are good diagnosticians, and that they know how to do a hysterectomy as well as anybody. They are clean operators, and will not infect the tissues around the field of operation, and yet look at their recurrences. I do not believe that there will ever be any method of total extirpation, high amputation, or any other operation, by which you will get 10 or 15 per cent. of recoveries. The technic of the operation is certainly well-known. You can not make any more room outside the cervix between it and the ureters and the pelvic vessels in woman in the future than you have now or in the past, and you can not get away from the cervix any further uniess you remodel the pelves of women.

As far as return in the scar is concerned, every man with whom I have ever talked or corresponded says that the return is in the sear. Kelly and Cullen say so; in fact, everybody says so, except Dr. Fiolischer, who says it does not return in the scar. Where is it? You feel it in the vaginal vault on either side. It may not be exactiy in the scar, but just at one side. a line not thicker than the edge of paper. 'The infiltration is right up to it, and bulging out on either side.

$I$ did not say that cancer of the cervix involves the bladder early. In cases where cancer begins in the anterior lip of the cervix, the bladder is liable to be involved early, and Dr. Kolischer substantiates this by reporting 15 eases out of 150 , or 10 per cent., where the blaclder was involved.

If radical operation is going to be done, I want to commena Dr. Werder's operation. No operation gives such good prospeets, from a theoretical as well as practical standpoint. Gentlemen, why should you remove the body of the uterus above the cervix when it is not diseased, with the hope of getting better results, when you do not get better results with total extirpation or radical operation than I do with my high amputation, or better than men did fifteen years ago with hign amputation? Why subject a woman to 10 per cent. of chances of mortality immediately after operation simply to do a radical operation? It is no trick, when you have the anterior and posterior peritoneal folds ;ight before you, to tie off the broad ligaments or: either side, and sew the edges of the vault together. The recurrence will be in the perimetric tissues, along the line of the cervix, anteriorly, posteriorly and laterally, and you can not take out any farther than up to the uterine vessels and ureters. Why, then, insist on taking out the body simply for the purpose of opening the peritoneun! There should be reason in all things, even in radicalism. I have seen men open the abdomen for a diseased tube and ovary on one side, but they took out everything on both sides as well as the uterus, because the ither side might become diseased later on-that is radicalism without reason.

Dr. Cusming (elosing the diseussion)-Appended to my paper is a pathologic report showing that the recurrence in iny case was a cancer, and not inflammatory tissue. In regard to the removal of glands in this operation, I think we must know from analogy of the operation for cancer of the breast and removal of the axillary glands that we get better results when that is done. In the last years the majority of operators have appreciated the danger of recurrence. Since the operation of tying off everything from above, closing everything from above, pulling the uterus down in bulk and cutting through the vagina from below, thus removing at once all infected tissues, there is a chance of doing the operation without infecting the tissues around, and consequently the result is better. I believe that this is the operation which will be done in the future, as, in my judgment, it gives better results.

The most common diseases in Alaska are said to be cerebrospinal meningitis, scorbutus, neuralgic form of rheumatism (inflammatory being very rare), alcoholism, insanity, digestive and nervous affections. Pneumonia is ahnost unknown. 